\title{
Nullification of European Patent: The Case of European Patent on Teff Flour Processing
}

\author{
Fikremariam Ghion, ", Biruk Haile ${ }^{2}$ \\ ${ }^{1}$ Genetic Resource Access and Benefit Sharing Directorate, Ethiopian Biodiversity Institute, Addis Ababa, Ethiopia \\ ${ }^{2}$ College of Law and Governance, Addis Ababa University, Addis Ababa, Ethiopia
}

Email address:

fikirghion80@gmail.com (F. Ghion)

${ }^{*}$ Corresponding author

\section{To cite this article:}

Fikremariam Ghion, Biruk Haile. Nullification of European Patent: The Case of European Patent on Teff Flour Processing. International Journal of Law and Society. Vol. 4, No. 3, 2021, pp. 193-202. doi: 10.11648/j.ijls.20210403.16

Received: July 17, 2021; Accepted: August 5, 2021; Published: August 31, 2021

\begin{abstract}
Various scientific studies and researches conclude that Ethiopia is a center of origin and diversity of Eragrostis Teff. Teff is a gluten free crop that has been originated and cultivated for centuries in Ethiopia. Due to its gluten free nature, most European and American consumers are fond this crop. This perhaps captures the interest of developed countries market which will contribute to the development and modernization of Ethiopia's agriculture on which the country's economy is massively dependent on. Conversely, as a result of the patent protection granted on Teff flour processing and the resultant gluten free Teff flour product made up of Teff and other gluten free and gluten containing crops in Europe, Ethiopia could not access European gluten free market. European patent on Teff flour processing granted by European Patent Organization (EPO) is still active and validated in some member countries to the European Patent Convention (EPC). Therefore, this research article will assess and evaluate the patentability requirements enshrined under EPC with the protection sought for Teff flour processing patent (Teff patent) granted by EPO. Further, domestic court decisions regarding Teff patent (decision of Hague court that hears the litigation between Ancientgrain BV vs. Bakels Senior NV) will also be analyzed to the extent relevant to this research article. At last, this article explores and discusses the domestic jurisdictions and laws that are necessary and instrumental for the invalidation/nullification of Teff patent.
\end{abstract}

Keywords: Teff Patent, EPC, EPO, Patent Invalidity and Infringement Action, Patent Revocation and Patent Claim

\section{Introduction}

The European patent system as it stands now is implemented by the European Patent Organization (EPO), which is established by the European Patent Convention of 1978 (EPC). [1] The result is a centralized system administered by EPO. [2] This makes it possible for an inventor to obtain a patent protection upon various European countries through a single application filed at the EPO or national offices of the EPC member countries. If a patent is granted as a result of a European Patent Application, then the resultant patent has the same effect in all contracting countries for which it is granted, have the effect of and be subject to the same conditions as a domestic patent granted by that country. [3] This concept is generally called a "bundle of patents" where the patent applicant has now a patent protection enforceable in all EPC member States that the patentee has paid national validation fee. [4] However, member States to the EPC are able to maintain their sovereignty over patent enforcement (ownership, validity, and infringement) since the EPC established that patent rights must be administered and enforced by the domestic laws of EPC member States. [5]

Based on EPC, EPO granted Teff flour processing patent (Teff patent) which covers 29 claims. [6] Teff patent covers the process and its end products of the process patent given where the products are derived directly from the application of the process patent given. [7] These processes and products includes inter alia, the falling numbers of Teff flour,[8] mixture of gluten free Teff flour with other glute free and gluten containing crops,[9] dough or batter,[10] food products or luxury food products,[11] method of making food products,[12] baked and pre-baked products,[13] and method 
of binding a composition. [14]

\section{European Patent Grant Procedure}

The duration of protection of EP is 20 years from the date of filling the patent application. [15] The grant of European Patent (EP) confers the same right like that of national patents granted by EPC member country that commences from the publication date on European Patent Bulletin. [16] And the patent application should have to pass formality and substantive requirements stipulated by the EPC.

\subsection{Formality Requirement}

EP procedure commences at the stage of filing patent application. After receiving the patent application, the EPO checks formality requirements has been met. Then it carries out a search and draws up a search report that mentions the documents which may be taken into consideration in deciding whether the invention to which the EP application relates is newness and inventiveness. Then the EPO publishes the patent application, together with the search report, after the expiry of a period of 18 months from the date of filing or, if priority from an earlier application is claimed, from the date of priority. [17] This search report accompanied by a non-public opinion, on whether the application and the invention to which it appear to meet the requirements of the EPC is sent to the patent applicant and is finalized in formality requirement.

\subsection{Substantive Requirements}

Apart from formality requirement, EP will be granted upon the fulfilment of substantive requirements contained within the EPC are met. These requirements are inter alia, the invention must not fall under non-patentable subject matter; it must have technical character; the invention must be new; it must be non-obvious; it must be sufficiently disclosed; and it must be useful. [18] And upon fulfilling these requirements, the EP will be granted that has the effects of a national patent granted in the EPC member countries. [19]

Although there is no agreed definition upon what exactly invention mean, it is common in Europe that an invention is new and it must involve technical solution to a technical problem. For example, invention may relate with the creation of an entirely new device, product, method or process.

The universal novelty requirement, as applied in most jurisdictions including EPO, it prevents the patenting of information that has been published in any form either through written, oral disclosure, disclosure by use or any use in anywhere in the world. [20] Mere discovery of something that is already found in nature without human ingenuity, creativity and inventiveness does not qualify as an invention.

An invention is considered to be new, if it is not part of the "state of the art", i.e. if it was not embodied in the public domain in the globe before the patent application in question. [21] The requirement of inventive step is designed to ensure that patents are only granted for creative and inventive solutions for a given problem, and not to the developments that a person with ordinary skill in the art/technology could simply construe from what is already exists in prior art. [22]

The invention must be disclosed the written description of an invention in sufficient detail so that any skilled person in the art can renovate and practice the invention from the descriptions and the drawings without exerting extra inventive effort. However, if the invention lacks this step, the patent may not be granted or may be revoked/nullified after it is challenged (either in a court action or patent offices). In addition, an invention must be useful for any kind of industry where it is granted. Finally, the patent application must not fall under the categories of non-patentable inventions or exceptions to. [23]

Then, the examining division of the EPO is of the view that the above steps are fulfilled, it may decide to grant the patent. Nonetheless, any person can file opposition for the grant of this patent within nine months of the grant. [24] Basically opposition procedure is to ensure that the patents are granted appropriately and wrongfully granted patents could be revoked by EPO. And if the party aggrieved by the decision of EPO, he/she/it file its notice of appeal to the EPO Boards of Appeal. [25]

From the above general feature, one can construe that European patent system is not exclusive and national routes are still open. For applicants interested in patent protection in one or more of EPC member countries, patent application at the EPO level is an attractive option and cost effective. [26]

\section{General Overview of Teff Genetic Resources}

\subsection{Agronomy and Nutrients of Teff Genetic Resources}

Ethiopia has one of the most bio-diverse country in the world with 74.3 million hectares of arable land ranges over 18 major agro ecological zones which makes it suitable to grow over 100 types of crops. [27] Due to agro ecological zone variations, Ethiopia has experienced diversified fauna and flora with a large variation in ecosystems and agricultural potential, ranging from pastoralist areas to moisture-reliable lowlands and highlands as well as drought-prone highlands and lowlands. [28] According to Nicolai Vavilov, Ethiopia is considered to be the center of origin and diversity for many economically important crops inter alia, Teff (Eragrostis Teff (Zucc.) Trotter) belongs to family Poaceae and genus Eragrostis. [29] Teff is originated and was domesticated in Ethiopia between 4000 - 1000 BC. [30] The genus Erafrostis genus has 350 species, of which and Teff is the only cultivated cereal species. [31] Until 2018, there are 44 registered Teff varieties are available in Ethiopia. [32]

At the Ethiopian Biodiversity Institute gene bank there are about 5,971 accessions of domesticated farmer varieties and 5 accessions of wild relatives of Teff, which is collected from various agro-ecological zones of Ethiopia. [31]

Teff has high nutritional values of protein, carbohydrate, fat, vitamin A and C, fiber, Thiamin, Riboflavin, Niacin, 
Calcium, Chloride, Chromium, Copper, Iron, Magnesium, Manganese, Phosphorus, Potassium, Sodium, Zinc and eight Essential Amino Acids (isoleucine, leucine, methionine, lysine, phenylalanine, threonine, tryptophan and valine). [33]

\subsection{Production and Consumption/Use of Teff}

In terms of production and consumption, Teff is the most important cereal crop in Ethiopia. It is relatively resistant to many abiotic and biotic stresses and can be grown under different agro-ecological zones. [34] Furthermore, it can also be stored for years without being seriously damaged by storage insect pests. [34]

As the most preferred staple food in Ethiopia, Teff fetches relatively higher price and important cash crop for farmers. [35] This top area crop counts for 3 million hectare of the cultivated land and in $2013 / 2014$, it was estimated that about 8 million producers or farmers (that is 43 percent of all Ethiopian) were involved in the production of Teff. [28, 36]

Linked with public support in agricultural research and development, Teff has been considered a priority crop with considerable public investment in its research and development. However, national productivity levels of Teff still remain low, though there is a slight increase over time (average yield reached 1.66 tons/ha in 2016) along with a low level of commercialization among smallholder farmers. [35] This has limited the extent to which the potential of Teff as an export commodity can be realized, especially since its globalization.

Ethiopian used Teff for the production of traditional food products, such as injera, sweet unleavened bread ("kita" and "anebabero"), opaque beer ("talla"), local spirit ("katikalla" or "arakie" or "shamit"), soups and gruels or porridge (muk). $[37,38]$ However, injera prepared from Teff is important food item consumed with spicy stew made from meat, beans, dairy products or cabbage. Various works have shown that in its injera making features (rollability, evenness of injera eyes, resilience, attractive flavor, freshness and slow staling over storage), Teff grain flours are superior than any other cereal flours. [39]

Through research, adaption or development of recipes, value added new food products of Teff could be developed. In recent years, Teff has been internationalized and has become an export commodity, given its nutrition value, thereby boosting its level of commercialization beyond the domestic market. For instance, in global north particularly United States and Europe, different Teff food products have been developed that directly targets gluten-intolerant people ( $2-4 \%$ of population). And this increases the popularity and demand for Teff flour and Teff-based products. [31]

\subsection{Marketing and Trading of Teff}

Due to absence of alternative cash crop (such as coffee, tea or cotton) and its higher price, Teff is a major commercial crop produced in producing areas of Gojjam and Shoa. [39] Trade in Teff operates through local markets and diverse actors comprising local assemblers, wholesalers, retailers, millers and, in recent years, Teff bread (injera) makers. Though the government wanted to include Teff in Ethiopian Commodity Exchange trade, this has not yet happened due to the challenges in setting up standard grades for determining quality.

Nevertheless, Teff is one of the commodities where quality of the variety is established on the basis of grain color and size and by the location where it is produced. [35] There are three conventional color-based grades for Teff (white, mixed and red). White and red Teff fetches the highest and lowest price consecutively. [40] Area of production is an important indicator of quality for each color, and Ada and Oloncomy (particular districts in East Shoa). [41]

As a result of its nutritional properties (high in fibre, calcium, iron and protein, low glycemic index and glutenfree nature), Teff has been labeled as the new super food in North American and European markets. [42]

Recognizing the importance of Teff in domestic consumption, the government has banned exports of both Teff grain and flour since 2006 (Teff grain and flour) so as to control domestic price hikes, which left producers limited to domestic market. [35] However, recently in 2015, the export of Teff flour was allowed, together with controlled export of Teff grain, through 48 farms licensed to produce for export. [35]

\section{Teff Patent and Scope of Protection}

\subsection{Overview of Teff Patent}

Teff patent was first filed in the Netherlands by Soil \& Crop Improvement BV on July 22, 2003. [6] The international filing date and the date of filing under EPO are 22 July 2004, [6] and Teff patent was granted by EPO on 10 January 2007. [6] And as per article 64 (1) of the EPC, the patent will expire after 20 year from its application, i.e. by 2024. The patent proprietor is stated as Health and Performance and Food International B.V. (HPFI) in the European Patent Specification published by EPO, whereas in the international application published under the Patent Cooperation Treaty by the World Intellectual Property Organization is given as S\&C B.V. [43] Jans Roosjen from Hooghalen in the Netherlands is mentioned as an inventor for all of the three patent publication. [44]

The granted Teff flour processing patent covers 29 product and process claims. Of them, there are two independent claims. [45] and the rest as dependent claims that are based their claim on other claims. And the patent also covers the end product of the process patent given where the products are derived directly from the application of the process patent given. [7] The followings are the scope of subject matters protected under the Teff flour processing patent granted by the EPO.

\subsection{The Scope of Teff Patent}

Since the Teff flour processing patent extends to the products derived from the application of the process that is 
protected by the patent right, the following are major claims that defines the scope of Teff patent.

\subsubsection{The Falling Numbers of Teff Flour}

Health and Performance Food International BV claims that the invention is related to gluten free flour of Teff grain with a falling number at the moment of grinding at least preferably 250, and most preferably at least 380 falling numbers. [8] Furthermore, a ripe grain of Teff flour that has a falling number at the moment of harvesting at least 1.05 , and most preferably 1.30 times higher. [46]

Falling number is an international standard of sprout measurement with the full name 'Hagberg Falling Number' which is widely used by baking industry to indicate flour quality of wheat and other cereals. [47] This method was developed by two persons (Sven Hagberg and Harald Perten) to determine the alpha amylase activity of wheat flour, but is now commonly used by the baking industry to indicate flour quality. [47] It indicates the alpha-amylase activity in the flour. [48] A high fall number means low alpha-amylase activity which indicate that the flour is less degraded by enzymes. [48] It is measured by heating the flour in water and measuring the rate of fall of a plunger. [48] As sprouted grain produces enzymes that breaks down starch, the ball will fall more quickly if the starch content is low, and this results in a lower falling number. [49] In 2001 it is disclosed to the general public that the common commercial minimum for making bread is 250 Hagberg fall number. [50]

\subsubsection{Mixture of Gluten Free Teff Flour with Other glute Free and gluten Containing Crops}

The other claim is a mixture of gluten free Teff flour with gluten free crops (potato, rice, corn, arrow root, buck wheat or quinoa) and gluten containing crops (wheat, barley, rye and oat) with a falling number higher than 400 and, more preferably 450 . Such a mixture is described as containing minimum values of iron, calcium and mineral binding substance. [9]

\subsubsection{Dough or Batter}

A dough or batter made up of gluten free Teff flour, a mixture of gluten free Teff flour with other gluten free crops stated above and a mixture of gluten free Teff flour with gluten containing crops are also protected. [10] Furthermore, the patent protection extended to extruded products or dry dough of at least products like pastas (macaroni, spaghetti, tagliatelle, lasagna, etc.) and noodles (vermicelli, thin Chinese noodles, chow mein, etc.). [50]

\subsubsection{Food Products or Luxury Food Products}

A food product is made up of gluten free Teff flour, a mixture of gluten free Teff flour with other gluten free crops stated above and a mixture of gluten free Teff flour with gluten containing crops. [51] Moreover, the patent claim states that a food product or luxury food product prepared from unground grain belonging to Eragrostis Teff at the moment of preparation with the falling number at least 250 and most preferably at least 380 . The protection conferred to these food products or luxury food products can be either in the form of solid (bread, pastry, cookies, pizza, pasta, crackers, biscuit, food bars, cornflakes, breadcrumbs, noodles, etc.) or liquid (beer). [50]

\subsubsection{Method of Making Food Products}

A method of baking gluten free Teff flour, a mixture of gluten free Teff flour with other gluten free crops or grain stated above and a mixture of gluten free Teff flour with gluten containing crops or grain as stated in the patent claim 19 and 20. According to the patent claim, the method for baking a product involves three steps. This includes:

a) Preparing a dough or batter by mixing flour with a liquid and, optionally, a leavening agent;

b) Kneading this dough into the desired shape; and

c) Heating the dough for some time. [12]

\subsubsection{Baked and Pre-baked Products}

The patent further include protection for pre-baked (which can be baked off at home by the consumer) and baked product of gluten free Teff flour, a mixture of gluten free Teff flour with other gluten free crops or grains stated above and a mixture of gluten free Teff flour with gluten containing crops. [13]

\subsubsection{Method of Binding a Composition}

Lastly, the patent claim cover methods for binding a composition made up of Teff flour, a mixture of Teff flour with other gluten free crops stated above and a mixture of Teff flour with gluten containing crops, preferably a pharmaceutical or cosmetic composition, of at least two components, involving mixing components with starch from flour produced according to the claims of the patent. [52] In relation to food, such thickening agent may, for instance, be used in soups and sauces. However, such a composition may also be used as a binding agent in a pharmaceutical composition such as a tablet, a capsule or coated tablet. [50]

\subsection{Prohibition and Their Effects}

Surprisingly, the wise strategy that the patentee has followed gave him/her/it wide margins of patent protection. The protection of Teff flour applies to any Eragrostis Teff varieties without distinction since their falling numbers are matched with the patent. In other words a flour of any variety of Eragrostis Teff can be a subject of this patent protection so long as the falling number of Ethiopian Teff varieties are matched with the falling numbers stated in the patent. In this connection with this, furthermore, it is worth mentioning that the Ethiopian Biodiversity Institute were conducted a falling number analysis of 22 Ethiopian Teff varieties in collaboration with Kaliti Food Share Company on May and June 2008, and the result revealed that the fall number these varieties ranged between 273 and 400+. [53] If these values are representative of Teff varieties in general, the Teff patent technically cover the processing of much of flour of Ethiopian Teff varieties. [53]

And this careful and wise strategy of patent application implies that the patent right categorically forbids anyone 
including Ethiopia to export any such products within the ambit of the protection given to the patentee except with a permission of the patentee. For instance, currently the market of designated European countries to the Teff patent is in principle closed for the Teff and a mixture of other gluten free and gluten containing flour; pre-baked and baking quality of such flour; all ripe grain of Teff varieties (if flour of such crop falls within the range of falling numbers); and all batter or dough made up of such flour, comprising the resultant products in either in liquid and solid form as stated above. This would practically prohibit Ethiopia to enter into any other agreement with another company to claim patent rights in these countries. In effect, it may also mean that Ethiopia may not be able to export its Teff based products to any of Teff patent designated countries.

\section{Teff Patent and EPC's Substantive Requirements}

\subsection{Novelty}

\subsubsection{Storage of Teff Grain}

The novelty requirement under Article 52 (1) of EPC states that the invention must be novel and it does not form part of the state of prior art. State of prior art means "everything made available to the public by means of a written or oral description, by use, or in any other way, before the date of filing of the European patent application". [54] This means, there is no qualification on the mode of prior art evidence (written, oral, photographic approach or otherwise) in which the technical information was made available to the general public.

In Teff patent, HPFI claimed that storing Teff grain after ripening for duration of 4-8 weeks and grinding it amounts to good baking quality of Teff flour. [55] However, storing Teff grain after harvesting is a matter of public knowledge before the patent application. Farmers are aware that storing Teff for longer time gives high economic benefits and flour quality. [56] Due to its nature, Teff can't seriously be damaged by common storage pests, and the longer time Teff is stored, the higher is its values. [57] In connection with this, the inventor of Teff patent also explains that he worked with Ethiopian farmers and this fact by itself justifies that the inventor learned variety of knowledge about post-harvest processing and storage of Teff that has existed for centuries. [58] Therefore, it can be argued that the inventor used postharvest and storage processes of Ethiopian farmers that have already existed before the application of the patent, and this defeats the novelty requirement.

\subsubsection{Falling Numbers of Teff Grain}

The falling numbers of Teff flour is another invention claimed by Teff patent. [57] According the description of Teff patent, customary Teff flour (Teff mixed with wheat flour to prepare injera) frequently leads to problems of instability of the product and unattractive taste. [59] Furthermore, description the patent mentioned that customary Teff flour has either too high or too low falling numbers that makes it unsuitable for baking quality. [60] And in order to solve such unattractiveness, instability and low baking quality of Teff flour, HPFI claimed that it invents falling number ranges from 250-380 second. [59]

However, in 2001 it is disclosed to the general public that the usual commercial minimum for making bread is 250 Hagberg fall number. [48] Therefore, it is not novel to describe a falling number range for baking of Teff product since such information is part of prior art. [48]

Moreover, the test of 22 Ethiopian Teff varieties revealed that their falling numbers varied from 273-400 seconds. [49] Such range of falling numbers is presumed to be the inherent genetic quality of Teff genetic resource but a creative solution for the problems mentioned by the inventor.

Further, The Hague Court in its decision of a suit between Ancientgrain BV vs Bakels Senior NV regarding two Dutch patents, NL 1023977 (processing post-matured Teff flour) and NL 1023978 (Flour mixture comprising Teff flour), conclude that the falling numbers mentioned by the patents are no longer an invention since $\mathrm{S} \& \mathrm{C}$ circulated Teff message to growers of Teff before its patent application. [61] Teff message mentions:

"Dutch Teff flour has too low falling numbers; a Teff flour from United States has too high fall numbers; a mixture of two ingredients baked well; the falling numbers is a value that indicates the quality of the starch (i.e. whether the flour can be used and baked); the Dutch Teff grain matures, giving it more favorable (higher) fall number" [61]

This message revealed that skilled person in baking industry can understand that flour with low falling number must be mixed with a flour with high falling numbers in order to get good baking quality and that the Dutch Teff grain ripens. [61] In other words, the mixture of too high and too low falling numbers of Teff flour will give a fall numbers of medium or good baking quality flour. [61] Since, Teff message reveals this information and it was communicated before the patent application, it is considered that such information belongs to prior art so that the claimed invention lack novelty. Therefore, the inherent genetic quality of Teff grain coupled with the information revealed by Teff message implies that the patent lacks novelty.

\subsubsection{Grinding of Teff Grain}

The other invention claimed by Teff patent is the grinding of Teff grain. The patent states that in order to get fine flour, it must pass through a sieve with a maximum pore size of at least 150 and at most 100 microns. [55] Description of Teff patent mentioned that customary Teff flour is usually not ground fine enough for baking quality because customary Teff flour is obtained by grinding the grain directly after harvest and this causes problem with the processing thereof in baked products. [60] In order to solve such problem and get fine flour, the grain must be stored at least 4 and at tmost 8 weeks after harvesting and grinding in order to gain good baking quality of flour. [60] Additionally; customary Teff flour is not usually ground fine enough and in order to get 
fine flour, the grinding of the Teff grain can be done according to conventional standard procedures for the preparation of flour using preferably pin-mill with integrated cooling. [60] Such description of invention with regard to grinding of Teff grain is not novel due to the fact that most of Ethiopian Teff varieties have the ability to produce Teff flour with a margin of 250-380 falling numbers. [49] Moreover, traditional storage of Teff grain for longer time will give finer flour for baking products. [57] Therefore, patent claim with regard to grinding of Teff grain via conventional standard or pin-mill does not amount to any new invention on Teff flour and the resultant product since the invention is a matter of public knowledge and natural feature of the Teff grain.

\subsection{Non-obviousness}

The other requirement under Article 52 (1) of the EPC is an inventive step. As per article 56 of EPC:

"An invention shall be considered as involving an inventive step if, having regard to the state of the art, it is not obvious to a person skilled in the art."

The issue of non-obviousness step will only follow when the invention is novel. [62] The word 'obvious' means an invention that follows plainly or logically from the prior art (written or otherwise evidence) or that doesn't go beyond the ordinary advancement of technology. [62] It is also something which doesn't involve the exercise of any skill or ability beyond what to be expected of the person skilled in that particular art. [62] If the claim of invention is something obvious to the person skilled in the art before the filing date, then the patent claim is deficient of inventiveness. [62]

The claimed inventions of Teff patent are allegedly obvious to person skilled in the respective art (post-harvest Teff process). Storage of Teff is evidenced by various prior art documents mentioned above. The inventive step followed in the falling numbers and fine dough was already known fact over Ethiopian Teff varieties. [49] It is a common knowledge that Teff grain is preferred to consume after being stored for longer period and only in rare case that it could be used immediately after harvest. [57] Description of Teff patent wrongly mentioned that injera is usually made from a mixture of Teff and wheat flour. [59] However, injera is widely and popularly prepared from unmixed Teff, whereas, the next popular injera is made from mixture of Teff with other cereal flour like barley, wheat, maize or sorghum. [57]

Since preparation of injera with Teff flour is old traditional practice in Ethiopia, the Court states that exclusion of injera from the patent claim was done deliberately so as to delineate the state of the art from the invention claimed. [61] And, it is clear from the context that Teff Message refers to the baking qualities of Teff flour for baking products other than injera. [61]

With regard to the preferred range of falling numbers, the court states that, skilled person who has read Teff message without inventive work has to get the claimed range by repeated baking test. [61] After all, it was known that the falling numbers which is expressed in seconds can vary between 61 and 600s. [59] The skilled person in the art can easily deduce the fall numbers of Teff flour from the United States is high according to the Teff message. [61] Whereas, the fall numbers of Dutch Teff flour was not yet available at that time, however, the Teff message discloses Dutch Teff flour fall number is too low, and to obtain good quality you mix both US and Dutch flours. [61] Therefore, the court concludes that, skilled person in the art can infer from the two extremes (61 and 600s) that you have to sit in the middle to get good baking quality and it is not an inventiveness to arrive at the claimed broad range (280-420s) in that search. [61] And baking method for product and mixture of Teff flour from another flour and moisture with any leavening agent, kneading and heating the dough, is very common baking method of general professional knowledge. [63] Mixing Teff flour with a flour of another crop cannot manifest inventive step because it is part of general professional knowledge. [57]

\subsection{Usefulness}

Industrial application is another condition of article 52 (1) of EPC. In order to fulfil this condition, any invention can be used in any industry of physical activity of technical character. [64] This may include various industries, including agriculture and food industries. Processes and product patent granted on Teff can be applied in area of food production and fulfils this requirement.

In light of Teff agreement, HPFI violates its obligation to communicate and get permission from the Ethiopian Biodiversity Institute for any innovative research proposals that has an effect to traditional knowledge associated with Teff genetic resource (ATK). [65] This is necessary in order to sort out possible confusion created between the research proposal and Ethiopian ATK. [65] However; HPFI never produced any research proposal to the Ethiopian Biodiversity Institute before it files its patent applications. Moreover, HPFI has an obligation that it do not access ATK associated with Teff without explicit written consent granted by Ethiopian Biodiversity Institute. [66] However, HPFI granted Teff patent in violation of article 4.5 and 4.6 of Teff agreement.

Although Teff patent is still active in United Kingdom, Italy, Belgium and Austria,[67] we can infer that the invention is not worthy of protection since it may not fulfill novelty and inventiveness steps. And there is possible evidence that can be adduced to nullify Teff patent in each jurisdiction which the patent is still active.

\section{Revocation and National Nullification Procedures}

\subsection{Revocation at EPO Level}

The EPC has an opposition and appeal procedure that governs post grant validity challenges which can be filed within the EPO (central opposition action). [69] EPO is the only body that has the competence to invalidate EP with the effect of EPC contracting countries. However, EPO's 
decision can also be challenged through appeal to the EPO's board of appeal. [69]

After the grant of EP, there are procedural steps one has to follow for the revocation EP called post grant opposition. [70]

Within the prescribed time limit, any person may file notice of opposition to the EPO over the granted EP. [71] The notice should contain relevant facts of a case, evidence and arguments in support of the ground of opposition. [72] Decision regarding the opposition applies to the EP in all contracting countries where the patent in question has effective. This makes the European opposition mechanism quite attractive for any potential challenger due to the scope of decision of opposition and cost. [73] In relation to Teff patent, however, the government of Ethiopia were not filed its opposition notice to the EPO within the prescribed three month period (10 January 2007- 09 April 2007). Since these period has lapsed without revoking the patent, and the only option left will be national nullification proceeding.

\subsection{National Nullification Procedures}

The other option to challenge Teff patent is available under the EPO member countries in which the patent protection is still active. [67] The EP, in each of the contracting countries of the EPC for which it is granted, have the effect of and be subject to the same conditions as a national patent granted by that country. [3] Also EP shall, in each contracting countries in respect of which it is granted confer on its proprietor the same rights as would be conferred by a national patent granted in that country. [16] Any infringement or validity of a EP shall be dealt with by domestic laws of EPC member countries. [74] And the forum for such litigation may be addressed to the national courts or patent offices as appropriate depending on the domestic legal and procedural framework of European countries where the patent protection is active. Currently, Teff patent in principle is active in Austria, United Kingdom, Belgium and Italy. [67] Recently Germany part of the Teff patent has been waived by the patent proprietor. [67]

Although the patent laws are in most part harmonized within the European countries, EPC member countries have their own procedural requirements of validation of a given EP. The followings discussions are designed to assess national invalidity/nullity procedures of individual European countries where the patent right is still active.

\subsubsection{United Kingdom}

In UK, unless there are reasonable grounds for distinguishing the case on its facts, previous decisions of higher courts are binding effect on lower courts. [75] Meaning, only the ratio decidendi or essential element of the judgment creates binding precedent for lower courts (stare decisis). [75] There is no bifurcated approach to the infringement and invalidity of patents in UK, rather both litigations can be brought before relevant courts and the defendant can bring his/her/its invalidity claim as a defense for infringement proceeding. [76]

\section{(i). Applicable law}

UK Patents Act of 1977 is the primary piece legislation in this regard. The elements of grounds for invalidation are listed under article 72 (1) of this law. A court may revoke/nullify a patent for an invention on the application of any person if the invention is not a patentable invention (inventions that lack newness, non-obviousness and usefulness requirements of the protection it sought). [77] These are similar provision with EPC counterpart that revocation proceeding can be based.

(ii). Competent organ for challenging the validity of patent

There is a combined system of filing patent infringement and invalidity claims to the same court (UK national patents and the UK designated EP). [76] Both patent invalidity and infringement proceedings can be litigated in the Patent County Court (PCC), which deals with cases that, are less complex and of a lower value, and the Patents High Court (PHC), which is a specialized court of Chancery Division of the High Court of Justice of England. [78] Decisions of these courts can be appealed to the Court of Appeal and Supreme Court of England. [78]

\subsubsection{Austria}

Austria has bifurcated patent litigation systems. This means that validity of patents are generally referred to the Austrian patent office's nullity division and suits involving infringement of patent are decided by courts. [79] Therefore, it is clear that invalidity proceeding cannot be asserted as a defense or counterclaim in infringement proceedings in Austria.

\section{(i). Applicable law}

The Austrian invalidity proceeding is mainly administered by the Austrian Patent Act of 1970. [80] Under the Austrian Patent regime, invalidity proceedings of Austrian patents and Austrian part of EP can be commenced, inter alia, on the basis of lack of patentability (lack of newness, nonobviousness, usefulness, subject matter of the patent falls under the exclusion of patentability) criteria. [81]

(ii). Competent organ for challenging the validity of patent Invalidity suit in the first instance is brought before the nullity division of the Austrian patent office. [82] And infringement cases can be brought before Courts. [83] Decisions may be appealed to the Higher Regional Court, and then to the Supreme Court. [84]

\subsubsection{Italy}

Italian laws foresee no bifurcation of the process: in the same proceedings, both infringement and invalidity of the patent can be litigated and decided by courts, in particular the enterprises courts (Tribunali delle Imprese). These courts have an exclusive jurisdiction over intellectual property litigation including proceedings for preliminary relief. [85]

\section{(i). Applicable law}

Under the Italian patent regime, the applicable law is the Italian Code of Industrial Property. [86] And as per this law, the invalidity of patent can be based on, inter alia, lack of novelty, inventiveness and industrial applicability which is similar to the EPC rules of opposition action. [87] 
(ii). Competent organ for challenging the validity of patent

The Italian courts have exclusive jurisdiction to deal with infringement and invalidity of patent claims concurrently in the same proceedings. [85] It means that the defendant in patent infringement proceeding can raise the invalidity/nullity of the patent as its defense/counter claim. And Italian Patent and Trademark Office or any other government body do not have jurisdiction over patent litigation and patent validity issues. [85]

\subsubsection{Belgium}

Since there is no bifurcated patent litigation process in Belgium, proceedings of infringement and invalidity of Belgian patents and Belgian validated EP are simultaneously heard by courts. [88] It means that validity of patents can be confronted in reaction to an infringement cases.

Since 2007, commercial courts along with national courts of appeal have been given exclusive jurisdiction to hear patent matters in first instance, including infringement and invalidity claims. [88] However, from 1 January 2015 onwards, only the Brussels Commercial Court is competent for patent cases heard at first instance. The Brussels Court of Appeal hears appeals and an appeal to the Supreme Court is possible on legal issues only. [84]

\section{(i). Applicable law}

The applicable law of European patent invalidation proceeding in Belgian patent regime is the Belgian patent law of 1997. [89] The patentable requirement under the Belgium law is similar with the requirements stipulated under the EPC, particularly, the requirement of newness, non-obviousness and usefulness of a given patent application, which is similar to the EPC patentability requirement. [90]

(ii). Competent court for challenging the validity of patent

Belgian courts can decide on the validity and infringement of patent. [88] It means that in infringement case, the defendant can submit invalidity claim as a defense or counter claim.

From the above jurisdictions, it can be inferred that invalidity/nullity actions can be based on inter alia; lack of novelty and inventive step of a given granted patent. The governance, courts procedures and forum for patent litigation is obviously varied in these jurisdictions. Despite such difference in the material element for invalidity action, the above mentioned jurisdictions provide similar grounds. It can be seen that The Hague court ruling on the Dutch part of EP on Teff was basically rely on evidences that are adduced for lack of novelty and inventiveness of the patent. As a result of membership to EPC and WTO-TRIPS Agreement, further, these jurisdictions have a harmonized patent regime that have essentially the same ground for invalidity actions. Consequently, Ethiopia could file individual patent invalidity/nullity actions in each of the above stated jurisdiction where Teff patent is validated based on essentially the same patentability requirements.

\section{Conclusion and Recommendation}

EPO grants such patent protection without adequate examination of prior art documents. For instance, there are literatures that describe the existence of prior art documents that contain information on post-harvest processing of Teff grain and good baking quality Teff flour. Moreover, the existence of Teff message analyzed by the court that judges the validity of Dutch Teff patent can be considered as an additional evidence that defeat the novelty and inventiveness of the patent. This is because, the Teff message was circulated before the application of Teff patent discloses that US Teff flour is too high and Dutch Teff flour is too low. It is obvious that one could get good baking quality of Teff flour by mixing both of US and Dutch Teff flours. This justifies that EPO grants such patent protection without adequate examination of prior art documents. And in order to invalidate or nullify the domestic protection of European patent on Teff, Ethiopia may file independent invalidity actions towards the existing Teff patent in EPC member countries as the Teff patent is still validated.

\section{References}

[1] See Art. 4 (1) of EPC.

[2] See Art. 4 (3) of EPC.

[3] See Art. 2 (2) of EPC.

[4] Aurora Plomer, 'A Unitary Patent for a (Dis) United Europe: The Long Shadow of History' [2015] 46 (5) International Review of Intellectual Property and Competition Law 520.

[5] See Art. 64 (3) of EPC.

[6] European Patent Specification, processing of Teff flour 'EP 1 646287 B1' (Teff Patent).

[7] See Art. 64 (2) of EPC.

[8] See claim 1 of Teff Patent.

[9] See claim 14 and 15 of Teff Patent.

[10] See claim 16 and 17 of Teff Patent.

[11] See claim 18 of Teff Patent.

[12] See claim 19 and 20 of Teff Patent.

[13] See claim 23 and 24 of Teff Patent.

[14] See claim 28 of Teff Patent.

[15] See Art. 63 (1) of EPC.

[16] See Art. 64 (1) of EPC.

[17] Cowan. R, Van der Eijk. W, Lissoni. F, Lotz. P, Van Overwalle. G, Schovsbo. J, (2007), Policy options for the improvement of the European patent system, European Parliament, p. 5.

[18] See Art. 52, 53, 54, 56 and 57 of EPC.

[19] See Art. 2 (1) of EPC.

[20] La flame. M. (2010), The European Patent System: An Overview and Critique, Houston Journal of International Law $32(3), 613$. 
[21] See Art. 54 of EPC.

[22] See Art. 56 of EPC.

[23] See Art. 52 and 53 of EPC.

[24] See Art. 99 of EPC.

[25] See Art. 21 of EPC.

[26] Cowan. R, Van der Eijk. W, Lissoni. F, Lotz. P, Van Overwalle. G, Schovsbo. J, (2007), Policy options for the improvement of the European patent system, European Parliament, p. 6.

[27] Agricultural Transformation Agency, Annual Report (ATA, 2018) $<$ http://www.ata.gov.et/wpcontent/uploads/2019/12/ANNUALREPORT-2011.pdf> accessed 6 April 2021.

[28] Minten, Bart, ed.; Taffesse, Alemayehu Seyoum, ed.; and Brown, Petra, ed. (2018). The economics of Teff: Exploring Ethiopia's biggest cash crop, International Food Policy Research Institute, 2.

[29] Girma, Abinet, ed. (2010), Teff: The Story of Ethiopia's Biodiversity, Forum for Environment, p. 6.

[30] Annette R Crymes. (2015), The International Footprint of Teff: Resurgence of an Ancient Ethiopian Grain, Arts \& Sciences Electronic Theses and Dissertations 394, 9.

[31] Agricultural Transformation Agency, 'Working Strategy for Strengthening Ethiopia's Teff Value Chain: Vision, Systemic Challenges, and Prioritized Interventions' (ATA, 2015) 20 $<$ http://www.ata.gov.et/download/working-strategy-forstrengthening-ethiopias-Teff-value-chain/ $>$ accessed 3 October 2019.

[32] Ethiopian Ministry of Agriculture and Natural Resource. (2018), Crop Variety Register, Issue 21, 8.

[33] Girma, Abinet, ed. (2010), Teff: The Story of Ethiopia's Biodiversity, Forum for Environment, p. 8.

[34] FAO. 2015. Analysis of price incentives for Teff in Ethiopia. Technical notes series, MAFAP, by Assefa B. Demeke M., Lanos B, Rome.

[35] Dawit Alemu and Kassahun Berhanu, (2018), The Political Economy of Agricultural Commercialization in Ethiopia: Discourses, Actors and Structural Impediments, Agricultural Policy Research in Africa, Working Paper 14. 30.

[36] Ethiopian institute of agricultural research, ' An Overview' (Crop Research, 6 June 2015) <http://www.eiar.gov.et/index.php/en/cropresearch $>$ accessed 14 June 2021>.

[37] National Research Council (1996), Lost Crops of Africa: Volume I: Grains, National Academies Press. 221.

[38] Asaye D. (2017), Screening of Teff (Eragrostis Teff) varieties for genotypic and phenotypic traits in Dejen Woreda, East Gojjam Zone, International Journal of Biodiversity and Conservation 9 (7), 240.

[39] Kebebew Assefa, Solomon Chanyalew and Zerihun Tadele (eds.) (2013). Achievements and Prospects of Teff Improvement; Proceedings of the Second International Workshop, November 7 9, 2011, Debre Zeit, Ethiopia. Ethiopian Institute of Agricultural Research, Addis Ababa, Ethiopia; Institute of Plant Sciences, University of Bern, Switzerland. Printed at Stämpfli AG, 3001
Bern, Switzerland, 221.

[40] Kebebew Assefa, Solomon Chanyalew and Zerihun Tadele (eds.) (2013). Achievements and Prospects of Teff Improvement; Proceedings of the Second International Workshop, November 7-9, 2011, Debre Zeit, Ethiopia. Ethiopian Institute of Agricultural Research, Addis Ababa, Ethiopia; Institute of Plant Sciences, University of Bern, Switzerland. Printed at Stämpfli AG, 3001 Bern, Switzerland, 6.

[41] Elleni Araya, 'Teff: Ethiopia's ancient grain not immune to rising food inflation' (Ethiopian Observatory, 2012) $<$ https://ethiopiaobservatory.com/2012/04/02/Teff-ethiopiasancient-grain-not-immune-to-rising-food-inflation-addisfortune/> accessed 8 September 2020.

[42] Bernandine Racoma, 'Introducing Teff, the New Super Grain from Ethiopia' (Day News, 2014) $<$ http://www.daynews.com/lifestyle/food-andbeverage/2014/01/introducing-Teff-new-super-grain-ethiopia$23530>$ accessed 24 December 2020.

[43] In the European Patent Specification published by the European Patent Office, the proprietor is listed as Health \& Performance Food International B.V., but in the International Application published under the Patent Cooperation Treaty by WIPO the applicant (for all designed countries except the USA) is listed as Soil \& Crop Cruise Control B.V. (in the USA the applicant is the same as the inventor, here listed as Jans Roosjen).

[44] European Patent Specification EP 1646287 B1 (Teff patent), United States Patent Application Publication US 2006/0286240 A1 and International Application published under the Patent Cooperation Treaty WO 2005/025319 A1.

[45] See claim 1 and 27 of Teff Patent.

[46] See claim 2 and 3 of Teff Patent.

[47] Sarah Best and Robert Muller. (1999), Use of the Hagberg Falling Number Apparatus to Determine Malt and Barley Quality, Journal of Institutional Brewery 77 (1), 273

[48] Farm-direct, 'Wheat-characteristics and uses' (Modern Wheat, 2001) $<$ http://www.farmdirect.co.uk/farming/stockcrop/wheat/wheatcurr.html> accessed 4 September 2019.

[49] Regine Andersen and Tone Winge, (2012), The Access and Benefit-Sharing Agreement on Teff Genetic Resources: Facts and Lessons, FNI, 52.

[50] See page 5 of Teff Patent.

[51] See claim 18 and page 16 of Teff Patent.

[52] See claim 28 and page 17 of Teff Patent.

[53] Regine Andersen and Tone Winge, (2012), The Access and Benefit-Sharing Agreement on Teff Genetic Resources: Facts and Lessons, FNI, 101.

[54] See Art. 54 (2) of EPC.

[55] See page 16 of Teff Patent.

[56] Beka Melkamu, Patenting Developing Countries' Traditional Knowledge As New Invention: An Examination of the Teff Processing Patent Claim by a Dutch Company and the Way Forward. in Yihdego and others (eds), Ethiopian Yearbook of International Law 2018 (Springer Nature Switzerland AG 2019) 76. 
[57] Seyfu Ketema. (1997), Teff Eragrostis Teff (Zucc) Trotter Promoting the conservation and use of underutilized and neglected crops, IPGRI, 17.

[58] Regine Andersen and Tone Winge, (2012), The Access and Benefit-Sharing Agreement on Teff Genetic Resources: Facts and Lessons, FNI, 109.

[59] See page 2 of Teff Patent.

[60] See page 3 of Teff Patent.

[61] Ancientgrain BV vs Bakels Senior NV [2018] ECLI: NL: RBDHA: 2018: 13960 (District Court of the Hague).

[62] European patent organization, 'Inventive step: General' (Guideline for Examination, 10 September 2019) $<$ https://www.epo.org/law-practice/legaltexts/html/guidelines/e/g_vii_1.htm> accessed 10 September 2020 .

[63] Alemayehu Refera, 'Teff Post-Harvest Operation' (FAO, 14 May 2001)

$<$ http://www.fao.org/fileadmin/user_upload/inpho/docs/Post Harvest_Compendium_-_TEFF.pdf $\bar{\varsigma}$ - accessed 10 October 2019 p. 37.

[64] See Art. 57 of European Patent Convention.

[65] See Art. 4.6 of The Agreement on Access to, and Benefit Sharing from Teff Genetic Resources, signed on April 5, 2005 (Teff agreement).

[66] See Art. 4.5 of Teff agreement.

[67] Amy Sandys, 'Heuking attempts to revoke Teff flour patent' (Juve Patents, 21 May 2019) <https://www.juvepatent.com/news-and-stories/cases/heuking-attempts-torevoke-Teff-flour-patent/> accessed 21 November 2019.

[68] See Art. 99-112 of EPC.

[69] See Art. 21 (1) and 106 (1) of EPC.

[70] According to Articles 52 to $57 \mathrm{EPC}$, the patent is not patentable or that the patent does not disclose the invention in a manner sufficiently clear and complete for it to be carried out by a person skilled in the art, or that the subject matter of the patent extends beyond the content of the application as originally filed.

[71] See Art. 99 (1) and 105 of EPC.

[72] See Rule 76 (2) (c) of Implementing Regulations to the EPC.

[73] Von Graevenitz, Georg; Wagner, STeffan; Harhoff, Dietmar; Hall, Bronwyn H.; Hoisl, Karin; Giuri, Paola; Gambardella, Alfonso (2007). The Strategic Use of Patents and Its Implications for Enterprise and Competition Policies, Report ENTR/05/82 for DG Enterprise, European Commission, 30.
[74] See Art. 138 (1) of EPC.

[75] Katharine Stephens and Audrey Horton (editor-Nicholas Catlin), The International Comparative Legal Guide to: Patents 2019, A practical cross-border insight into patent law, 9th edition, Global Legal Group Ltd., 216.

[76] WIPO, 'An overview of patent litigation systems across jurisdictions' (Special theme, 2018) $<$ https://www.wipo.int/edocs/pubdocs/en/wipo pub 941201 8-chapter1.pdf $>$ accessed 1 July 2021.

[77] See Art. 72 (1) (a) of UK Patent Act of 1977.

[78] Christian Helmers and Luke Mcdonagh, 'Patent litigation in the UK: an empirical survey $2000-2008$ ' [2013] 8 (11) Journal of Intellectual Property Law \& Practice 846.

[79] Nick beckett and jeremy morton, Austria. in Nick Beckett and Jeremy Morton (eds), International Patent Litigation Guide (CMS 2013) 5.

[80] WIPO, 'Law on Patents 1970 (as amended up to Federal Law No 234/1984 published in the Federal Law Gazette (BGBI No 234/1984))' (Austria, 2018) $<$ https://wipolex.wipo.int/en/text/124832> accessed 2020.

[81] See Art. 48 of the Austrian Patent Act of 1970.

[82] Walter Holzer, 'Effective Mechanisms for Challenging the Validity of Patents' (WIPO, 2006) $<$ https://www.wipo.int/export/sites/www/meetings/en/2006/sc p_of_ge_06/presentations/scp_of_ge_06_holzer.pdf $>$ accessed 4 July2020.

[83] Council of European Union, 'Towards an Enhanced Patent Litigation System and a Community Patent - How to Take Discussions Further' (Working document, 2007) $<$ https://data.consilium.europa.eu/doc/document/ST\%2011622 $\% 202007 \% 20$ INIT/EN/pdf> accessed 4 July2020.

[84] European patent academy, 'Proceedings for invalidity' (European Patent Organization, 2015) <https://ecourses.epo.org/wbts_int/litigation/ProcInvalidity.pdf> accessed 4 July 2020 .

[85] Licia Garotti, Italia. in Trevor Cook (ed), Patent Litigation Law Review (Law Business Research Ltd 2019) 168.

[86] Italian Code of Industrial Property, effective from 2 September 2010.

[87] See Art. 76 of Italian Code of Industrial Property.

[88] Stuart JH Graham and Nicolas Van Zeebroeck, 'COMPARING PATENT LITIGATION ACROSS EUROPE: A FIRST LOOK' [2014] 17 STANFORD TECHNOLOGY LAW REVIEW 678

[89] Belgium Patent Law of 1997.

[90] See Art. 5, 6 and 7 of Belgium Patent Law of 1997. 